\title{
Stability comparison of parental and modified double cross maize hybrids
}

\author{
Syed Majid Rasheed ${ }^{1 *}$, Hidayat-ur-Rahman ${ }^{2}$ and Syed Salim Shah ${ }^{1}$ \\ 1. Department of Plant Breeding and Genetics, Bacha Khan University, Charsadda-Pakistan \\ 2. Department of Plant Breeding and Genetics, The University of Agriculture, Peshawar-Pakistan \\ *Corresponding author's email: smrasheed@bkuc.edu.pk \\ Citation \\ Syed Majid Rasheed, Hidayat-ur-Rahman and Syed Salim Shah. Stability comparison of parental and modified \\ double cross maize hybrids: Pure and Applied Biology. Vol. 6, Issue 1, pp108-115.
}

http://dx.doi.org/10.19045/bspab.2017.60003

\begin{tabular}{llll}
\hline \hline Received: 28/09/2016 & Revised: 03/01/2017 & Accepted: 08/01/2017 & Online First: 11/01/2017 \\
\hline \hline
\end{tabular}

\section{Abstract}

The objective of this study was to study the level of grain yield reduction in modified double cross maize hybrids in comparison with their parental hybrids. Yield performance and stability comparison for yield and yield associated parameters for modified double cross maize hybrids and their respective standard parental hybrids was carried out across three locations of Khyber Pakhtunkhwa i.e., The University of Agriculture (UAP), Agricultural Research Station (ARS) Baffa (Mansehra) and Cereal Crops Research Institute (CCRI), Pirsabak (Nowshera), during 2009-10. Modified double cross hybrids of maize having improved yield were produced during spring crop season 2009 at Malakandher Research farm of University of Agriculture, Peshawar. Genotype $\mathrm{x}$ environment interaction was studied for yield and yield parameters in five modified double cross maize hybrids and their respective parental maize hybrids. Genotype main effect and genotype $\mathrm{x}$ environment interaction effect revealed significant differences for all parameters, except grain moisture at harvest which exhibited non-significant differences. Based on stability parameters and over all mean, the performance of modified double cross hybrid WD-2x8 across different environments excelled other parental hybrids as well as modified hybrids. Selection of modified hybrid WD-2x8 for ear length, ear diameter, 300 kernel weight and grain yield could enhance the grain yield in the target environments and it could be recommended as suitable and stable genotype for locations similar to the target environments. It can be inferred that the production of modified double cross hybrids could be beneficial, as the yield of modified double cross hybrids were almost at par with their respective parental maize hybrids.

Keywords: Finlay-Wilkinson stability analysis; Modified double cross maize hybrids; Yield and yield related traits

\section{Introduction}

Genotype $\mathrm{x}$ environment interactions (GEI) are of considerable importance to the plant breeders in developing improved genotypes. When genotypes are compared over a series of environments, the relative ranking usually shows relative superiority of any variety. The genotype $\mathrm{x}$ environment interaction
(GEI) is one of the major challenges in plant breeding not only in the selection procedure but in cultivar recommendation as well [1]. When the performance ranking of genotypes over environments is not constant, the identification of cultivars with high adaptability and predictable performance under specific or general environmental 
conditions is an option to deal with this fact [2].

Grain yield, is quantitative in nature and routinely exhibit GEI. This necessitates genotype evaluation in multi-environments trials in the advanced stages of selection [3]. However, prominent $\mathrm{G} \times \mathrm{E}$ interactions decreases relationship between phenotype and genotype and also genetic improvements in breeding programmes [4]. In this situation, stability analysis is needed which is defined as ability of a certain variety to maintain stable yield under changing environmental conditions [5]. [6] earlier suggested that separation of important $\mathrm{G} \times \mathrm{E}$ interactions found in regression analysis into elements is needed as stability criteria. Afterwards, the same regression model was used by other authors to produce different stability criteria. [7] used regression coefficient (bi) of the linear regression of individual genotypic yield on the mean yield of all genotypes for each environment; while [8] used the variance of deviations $\left(\mathrm{S}^{2} \mathrm{di}\right)$ from regression as a potential criteria for deciding stability of a genotype.

Maize (Zea mays L.), being one of the important cereal crops in the world and in Pakistan after wheat and rice, is grown all over the country. Newly improved cultivars generally need to be tested at several planting dates or sites and for several years before being recommended for a given site. The main environmental effects (E) and genotype environment interaction (GE) have been reported as the most important sources of variation for the measured yield of crops $[9,10]$. Farmers are more interested in cultivars that produce consistent yields under their growing conditions and breeders also desire a broad range of adaptability for their cultivars. Hence, the information on GE interaction and stability is of paramount importance for maize breeders and farmers. Maize hybrids are reported to give higher yields under good management than open pollinated varieties of similar maturity [11, 12]. However, these require a specific crop production package and are prone to changes in environmental condition. This results in changes in performance of maize hybrids across environments.

In third world countries, like Pakistan, the farmers due to resource constraints cannot afford the expensive hybrid see every season and generally prefer local cultivars. The use of old cultivars is usually quoted as the prime cause of low average production of maize per unit area in these countries than the developed ones. As the standard single and double cross hybrids are comparatively expensive, therefore some new avenues need to be explored to produce modified double cross maize hybrids which could be comparatively less expensive than the standard single and double cross maize hybrids. The development of modified double cross hybrids in cross pollinated crops like maize could be simple and easier as compared to the commercial hybrids. If the level of yield reduction from modified double cross hybrids could be negligible, it can be used as seed for new crop in subsequent years. The present study was therefore aimed at the production modified double cross hybrids of maize having improved grain yield and to investigate the stability in yield and yield parameters associated with modified double cross maize hybrids compared with their respective standard parental hybrids across different maize growing areas of Khyber Pakhtunkhwa.

\section{Materials and methods}

The development of modified double cross hybrids from the available maize hybrids was carried out at the Malakandher Research Farm of University of Agriculture Peshawar (Pakistan) during spring season (Feb-June) 2009. Five different single cross maize hybrids of nearly similar maturity were 
sown in isolation in such a way that two rows of single cross maize hybrids were used as female which were followed by an alternate row of male hybrid parent. Male hybrid rows were sown from the bulk comprising seed of all hybrid parents in equal proportion. Female parent rows were detasseled before flowering to prevent selffertilization. Male parent hybrids were allowed to open pollinate the silks of the female parent. Early maturing ears of female parents were selected accompanied with other superior attributes for further evaluation in a replicated experiment over four environments.

The evaluation and stability trial of modified double cross hybrids was conducted during July 2009-10 and 2011 using randomized complete block design with three replications. Five modified double cross maize hybrids and their respective parental hybrids were planted in two rows having five meter length, keeping plant-to-plant distance of $25 \mathrm{~cm}$ and row-to-row distance of $75 \mathrm{~cm}$. A basal dose of fertilizer containing nitrogen and phosphate at the rate of $41 \mathrm{~kg}$ and $20 \mathrm{~kg} \mathrm{ha}^{-1}$, respectively were applied at the time of seed bed preparation just before sowing. Second doze of fertilizer was side dressed at knee high stage of the crop. Experimental plot was irrigated as and when needed, however, adequate moisture was maintained during the entire growing period particularly during flowering. Standard culture practices were applied from sowing to harvest (Table 1).

Table 1. Presented detail of the four environments and sowing year

\begin{tabular}{|l|l|l|}
\hline Environment & Year & Location \\
\hline 1 & 2009 & Agriculture Research Station, Baffa, Mansehra \\
\hline 2 & 2009 & Malakandher farm, University of Agriculture, Peshawar \\
\hline 3 & 2010 & Malakandher farm, University of Agriculture, Peshawar \\
\hline 4 & 2011 & Cereal Crop Research Institute, Pirsabak, Nowshera \\
\hline
\end{tabular}

The following modified double cross maize hybrids and their parents were used in this study (Table 2).

Table 2. Presented modified double cross maize hybrids and their parents

\begin{tabular}{|c|c|}
\hline Modified Double Cross Maize Hybrids & Parental Hybrids \\
\hline Opener & Opener \\
\hline Hicorn & Hicorn \\
\hline WD-2 $~ 8$ & WD-2 8 \\
\hline CS-2Y2 8 CS-2Y2 \\
\hline CS-King & CS-King \\
\hline
\end{tabular}

Data were recorded on kernel rows ear ${ }^{-1}$, ear length, ear diameter, grain moisture at harvest, 300 kernel weight and grain yield Grain yield $\left(\mathrm{kg} \mathrm{ha}^{-1}\right)=$ Field wt. $\times(100$-grain moisture content $) \times 0.8 \times 43 \times 10,000$

$$
n \times 85 \times 7.5
$$

$10,000=$ Area of hectare in square meters $\mathrm{n}=$ Number of plants harvested.

Statistical analysis: The experimental data were subjected to the analysis of variance $\mathrm{ha}^{-1}$. Grains were harvested at full crop maturity and grain yield was determined with the help of the following formula: appropriate for RCB design using statistical software M Stat C. Upon significant Fvalue, the data was further subjected to 
Finlay and Wilkinson's [7] model for stability analysis.

\section{Results and discussion}

Mean square values for kernel rows ear ${ }^{-1}$, ear length, ear diameter, grain moisture at harvest, 300-kernel weight and grain yield ( $\mathrm{t}$ $\mathrm{ha}^{-1}$ ) are given in table 3 . Highly significant variation across four environments was observed for all parameters, except grain moisture at harvest where non-significant differences were evident. Highly significant differences among genotypes across the four environments were observed for ear diameter and fresh ear weight plot $^{-1}$, while significant differences were obvious for kernel rows ear ${ }^{-1}$, ear length, 0-kernel weight and grain yield $\left(\mathrm{t} \mathrm{ha}^{-1}\right)$. [13] also reported significant differences among maize genotypes for grain yield. The interaction between hybrids and locations were highly significant for kernel rows ear ${ }^{-1}$, ear length, 300 -kernel weight and grain yield $\left(\mathrm{t} \mathrm{ha}^{-1}\right)$, revealing that these parameters were considerably influenced by the environmental variations encountered across the four environments. However, nonsignificant differences were found for grain moisture at harvest, indicating stability of this parameter across the tested environments, during the present study.

Table 3. Pooled analysis of variance for stability of kernel rows ear-1, ear length, ear diameter, grain moisture at harvest, 300-kernel weight and grain yield over four environments

\begin{tabular}{|l|l|l|l|l|l|l|l|}
\hline $\begin{array}{l}\text { Source of } \\
\text { variation }\end{array}$ & df & $\begin{array}{l}\text { Kernel } \\
\text { rows ear }\end{array}$ & Ear length & $\begin{array}{l}\text { Ear } \\
\text { diameter }\end{array}$ & $\begin{array}{l}\text { Grain } \\
\text { moisture } \\
\text { at harvest }\end{array}$ & $\begin{array}{l}\text { 300 kernel } \\
\text { weight }\end{array}$ & Grain yield \\
\hline $\begin{array}{l}\text { Environment } \\
\text { (Env) }\end{array}$ & 3 & $15.444^{* *}$ & $91.3413^{* *}$ & $0.1863^{* *}$ & $17.7246^{\mathrm{NS}}$ & $2651.564^{* *}$ & $49.5804^{* *}$ \\
\hline Reps (Env) & 8 & 0.8917 & 1.4749 & 0.0575 & 5.2180 & 123.4275 & 0.6308 \\
\hline $\begin{array}{l}\text { Genotypes } \\
\text { (Gen) }\end{array}$ & 9 & $1.4778^{*}$ & $3.3930^{*}$ & $0.2126^{* *}$ & $6.1341^{\mathrm{NS}}$ & $247.6596^{*}$ & $3.7941^{*}$ \\
\hline Gen x Env & 27 & $1.2778^{*}$ & $3.2999^{*}$ & $0.0694^{*}$ & $7.8520^{\mathrm{NS}}$ & $190.5866^{*}$ & $4.4023^{* *}$ \\
\hline Error & 72 & 0.6694 & 1.6505 & 0.0375 & 8.6080 & 111.7340 & 1.8632 \\
\hline
\end{tabular}

$*, * *=$ Significant and highly significant at 5 and $1 \%$ respectively

The mean values for kernel rows ear ${ }^{-1}$, ear length, ear diameter, grain moisture at harvest, 300-kernel weight and grain yield ( $\mathrm{t}$ $\mathrm{ha}^{-1}$ ), of modified double cross maize hybrids and their respective parental hybrids at four environments are given in table 4 and 5 .

Maximum and minimum mean values for kernel rows ear $^{-1} \quad(14.6$ and 13.3, respectively), across four environments, was attained by hybrid Hicorn and hybrid Opener respectively. Modified double cross hybrid Opener showed the highest mean value for ear length $(17.75 \mathrm{~cm})$ while the lowest mean value was recorded for modified double cross hybrid Hicorn (15.86 $\mathrm{cm})$. Remaining hybrids were having their mean values within this range. The mean values for ear diameter revealed that significant differences were exhibited by the genotypes for the trait. Maximum ear diameter was attained by hybrid Hicorn $(4.90 \mathrm{~cm})$ followed by hybrid CS-2Y2 and modified hybrid WD 2x8, while minimum ear diameter was attained by hybrid WD $2 \times 8$. Non-significant differences were observed among the genotypes across the four environments for grain moisture percent. Mean values for 300-kernel weight ranged between $95.17 \mathrm{~g}$ and $108.11 \mathrm{~g}$. Maximum 300-kernel weight of $108.11 \mathrm{~g}$ was recorded for modified hybrid WD-2x8, 
followed by modified hybrid CS-2Y2 with average 300-kernel weight of $107 \mathrm{~g}$. Minimum 300-kernel weight $(95.17 \mathrm{~g})$ was observed for modified hybrid Hicorn. Mean grain yield varied between 6.67 and $8.43 \mathrm{t}$ $\mathrm{ha}^{-1}$. Maximum grain yield was observed for the modified hybrid WD-2x8 followed by modified hybrid Hicorn (8.13 $\left.\mathrm{t} \mathrm{ha}^{-1}\right)$ and modified hybrid CS King (8.03 $\left.\mathrm{t} \mathrm{ha}^{-1}\right)$. Hybrid WD-2x 8 showed minimum average grain yield of $6.67 \mathrm{t} \mathrm{ha}^{-1}$ across four environments. It is obvious from table 6 that modified hybrid WD-2x8 ranked first with average yield of $9.96 \mathrm{t} \mathrm{ha}^{-1}$ at ARS, Baffa, Mansehra, followed by modified hybrid CS King, at UAP, with average yield of $9.89 \mathrm{t}$ $\mathrm{ha}^{-1}$. The lowest yield was $3.65 \mathrm{t} \mathrm{ha}^{-1}$ produced by hybrid CS- King at UAP. Mean square values for grain yield per hectare also showed that all the hybrids were significantly different from each other at all environments.

Table 4. Means (Xi), Regression response indices (bi) and deviation from regression $\left(\mathrm{S}^{2} \mathrm{di}\right)$ for various maize genotypes

\begin{tabular}{|c|c|c|c|c|c|c|c|c|c|}
\hline \multirow{2}{*}{$\begin{array}{l}\text { Modified } \\
\text { double cross } \\
\text { hybrids }\end{array}$} & \multicolumn{3}{|c|}{ Kernel rows ear-1 } & \multicolumn{3}{|c|}{ Ear length $(\mathrm{cm})$} & \multicolumn{3}{|c|}{ Ear diameter $(\mathrm{cm})$} \\
\hline & $\begin{array}{l}\text { Mean } \\
\text { (Xi) }\end{array}$ & bi & $\mathbf{S}^{2} \mathrm{di}$ & Mean $(\mathrm{Xi})$ & bi & $\mathbf{S}^{2} \mathrm{di}$ & $\begin{array}{l}\text { Mean } \\
\text { (Xi) }\end{array}$ & bi & $S^{2}$ di \\
\hline Opener & 14.0 & 1.10 & 0.54 & 17.8 & 1.01 & 0.89 & 4.57 & 1.35 & 0.11 \\
\hline HiCorn & 14.2 & 0.77 & 0.70 & 15.9 & 1.26 & 1.07 & 4.66 & 0.69 & 0.14 \\
\hline WD-2 x 8 & 14.2 & 0.60 & 0.56 & 17.6 & 0.71 & 0.83 & 4.78 & 0.05 & 0.29 \\
\hline CS-2Y2 & 13.9 & -0.01 & 0.71 & 16.8 & 0.94 & 1.29 & 4.57 & 1.09 & 0.13 \\
\hline CS-King & 14.3 & 1.42 & 0.34 & 16.9 & 0.29 & 0.60 & 4.58 & 0.68 & 0.03 \\
\hline \multicolumn{10}{|c|}{ Parental hybrids } \\
\hline Opener & 13.3 & 1.81 & 0.69 & 17.4 & 1.74 & 0.87 & 4.60 & 3.09 & 0.09 \\
\hline HiCorn & 14.6 & 0.65 & 0.40 & 16.7 & 0.99 & 0.37 & 4.90 & 0.42 & 0.03 \\
\hline WD-2 x 8 & 14.0 & 1.73 & 0.68 & 16.9 & 0.57 & 0.88 & 4.47 & 0.51 & 0.09 \\
\hline CS-2Y2 & 14.3 & 1.02 & 0.55 & 17.1 & 1.36 & 1.18 & 4.79 & 0.81 & 0.05 \\
\hline CS-King & 13.8 & 0.91 & 0.72 & 17.1 & 1.12 & 0.29 & 4.74 & 1.32 & 0.32 \\
\hline Average & 14.1 & 1.00 & & 17.02 & 0.99 & & 4.66 & 1.02 & \\
\hline
\end{tabular}

Table 5. Means (Xi), Regression response indices (bi) and deviation from regression $\left(\mathrm{S}^{2} \mathrm{di}\right)$ for various maize genotypes

\begin{tabular}{|c|c|c|c|c|c|c|c|c|c|}
\hline \multirow{2}{*}{$\begin{array}{l}\text { Modified } \\
\text { double } \\
\text { cross } \\
\text { hybrids }\end{array}$} & \multicolumn{3}{|c|}{$\begin{array}{c}\text { Grain moisture at } \\
\text { harvest }(\%)\end{array}$} & \multicolumn{3}{|c|}{$\begin{array}{l}300 \text { - kernel } \\
\text { weight }(\mathrm{g})\end{array}$} & \multicolumn{3}{|c|}{$\begin{array}{c}\text { Grain yield } \\
\left(\mathrm{t} \mathrm{ha}^{-1}\right)\end{array}$} \\
\hline & $\begin{array}{l}\text { Mean } \\
(\mathrm{Xi})\end{array}$ & bi & $\mathrm{S}^{2} \mathrm{di}$ & $\begin{array}{l}\text { Mean } \\
(\mathrm{Xi})\end{array}$ & bi & $\mathrm{S}^{2} \mathrm{di}$ & $\begin{array}{l}\text { Mean } \\
(\mathrm{Xi})\end{array}$ & bi & $\mathrm{S}^{2} \mathrm{di}$ \\
\hline Opener & 26.95 & 2.35 & 2.00 & 102.15 & 1.03 & 5.25 & 7.85 & 1.36 & 0.17 \\
\hline HiCorn & 26.84 & -0.95 & 0.46 & 95.17 & 0.53 & 1.75 & 8.13 & 0.88 & 0.40 \\
\hline WD-2 x 8 & 26.26 & 2.03 & 0.96 & 108.11 & 1.69 & 4.52 & 8.43 & 0.90 & 0.87 \\
\hline CS-2Y2 & 26.73 & 0.01 & 0.07 & 107.00 & 0.36 & 7.39 & 7.70 & 0.48 & 0.99 \\
\hline CS-King & 26.24 & 0.74 & 0.64 & 100.00 & 0.59 & 8.77 & 8.03 & -0.27 & 1.55 \\
\hline \multicolumn{10}{|c|}{ Parental hybrids } \\
\hline Opener & 27.98 & 2.12 & 1.21 & 105.98 & 1.27 & 12.94 & 7.54 & 1.74 & 0.34 \\
\hline HiCorn & 26.04 & 3.94 & 0.48 & 102.69 & 1.06 & 7.22 & 8.00 & 0.50 & 0.42 \\
\hline WD-2 $\times 8$ & 27.49 & -0.97 & 1.66 & 95.55 & 1.25 & 8.03 & 6.67 & 0.42 & 0.88 \\
\hline CS-2Y2 & 28.09 & -0.98 & 0.98 & 99.24 & 1.10 & 11.30 & 7.51 & 1.82 & 0.51 \\
\hline CS-King & 27.27 & 1.72 & 1.18 & 98.85 & 1.12 & 8.58 & 6.80 & 2.21 & 0.99 \\
\hline Average & 26.99 & 1.00 & & 101.47 & 1.00 & & 7.66 & 1.00 & \\
\hline
\end{tabular}


Table 6. Grain yield ( $\left.\mathrm{ha}^{-1}\right)$ of modified double cross maize hybrids and their respective parental hybrids across four environments

\begin{tabular}{|l|c|c|c|c|}
\hline $\begin{array}{l}\text { Modified double } \\
\text { cross hybrids }\end{array}$ & $\begin{array}{l}\text { ARS, Baffa, } \\
\text { Mansehra 2009 }\end{array}$ & $\begin{array}{l}\text { UAP, Peshawar } \\
\mathbf{2 0 0 9}\end{array}$ & $\begin{array}{l}\text { UAP, Peshawar } \\
\mathbf{2 0 1 0}\end{array}$ & $\begin{array}{l}\text { CCRI Pirsabak, } \\
\text { Nowshera 2011 }\end{array}$ \\
\hline Opener & 9.36 & 6.33 & 6.34 & 9.36 \\
\hline HiCorn & 9.46 & 7.42 & 6.91 & 8.74 \\
\hline WD-2 x 8 & 9.96 & 8.21 & 6.75 & 8.78 \\
\hline CS-2Y2 & 7.24 & 7.51 & 6.87 & 9.16 \\
\hline CS-King & 9.89 & 6.93 & 7.31 \\
\hline Parental hybrids & 7.99 & 5.46 & 5.72 & 9.57 \\
\hline Opener & 9.42 & 7.69 & 7.23 & 8.17 \\
\hline HiCorn & 8.93 & 5.33 & 6.98 & 7.27 \\
\hline WD-2 x 8 & 7.11 & 5.26 & 5.69 & 9.85 \\
\hline CS-2Y2 & 9.25 & 3.65 & 4.97 & 9.70 \\
\hline CS-King & 8.89 &
\end{tabular}

Stability analysis

Once the genotype $x$ environment interaction was found to be significant, the next test was to identify stable genotypes, with minimum interaction with the environments. Several stability models have been developed to identify the stable genotype. Finlay and Wilkinson (1963) model is one which has been used by researchers commonly to estimate stability in maize and other crops. According to [7], linear regression associated with high mean yield is used as measure of stability. Genotypes with regression coefficient of 1.0 and high mean yield indicate average stability and general adaptation. However, genotypes with low mean yield are poorly adapted to all the environments. Regression values greater than one describes genotypes with increasing sensitivity to environmental changes but adopted to favourable environments. Regression coefficients less than 1.0 provide a measure of greater resistance to environmental changes and therefore increasing specificity of adaptability to low-yielding environments.

The data on stability parameters i.e. mean performance $(\mathrm{Xi})$, regression coefficient (bi) for different parameters are presented in Table 2 and 3. Wide range of stability among the modified hybrids and respective parental hybrids are evident from regression coefficient values of parameters studied during the investigation. Hybrid CS-2Y2 proved to be more stable and generally adaptable genotype for kernel rows ear ${ }^{-1}$, it has regression coefficient $(\mathrm{bi}=1.02)$ with average kernel rows of 14.3. Hicorn showed regression coefficient (bi $<1=0.65$ ) and exhibited maximum kernel rows (14.6), hence showed less fluctuation to environmental changes and better adaptability to low yielding environments.

A perusal of stability parameters for ear length $(\mathrm{cm})$ indicated that out of ten genotypes, modified hybrid Opener (17.8 $\mathrm{cm})$ registered higher ear length and showed bi value equal to unity (1.01). Modified hybrid WD-2x8 (X = $17.6 \mathrm{~cm})$ had regression coefficient value less than unity (bi $=0.71)$ hence indicating the adaptability of the genotype under unfavourable conditions. Hybrid Opener exhibited above average $(17.4 \mathrm{~cm})$ ear length but it was more sensitive to environmental changes ( $\mathrm{bi}=$ 1.74) thus it could not be considered stable for this parameter across all the environments. It is revealed from Table 2 that modified hybrids were generally more stable and showed better performance even under unfavourable conditions as compared to parental hybrids which were comparatively more sensitive to environmental changes. 
Selection for a character such as ear width could lead to considerable improvement in grain yield [14]. The regression coefficient value for 10 maize genotypes for ear diameter ranged from 0.42 to 3.09. Based on the stability parameters none of the genotype could be considered as ideally stable across four environments, however hybrid CS-2Y2 and hybrid Hicorn $(\mathrm{X}=4.79$ and $4.90 \mathrm{~cm}$, bi $=0.81$ and 0.42 ) and modified hybrid WD$2 \times 8(\mathrm{X}=4.78 \mathrm{~cm}$, bi $=0.05)$ performed better for this parameter under unfavourable conditions. These genotypes had maximum ear diameter and had regression coefficient less than unity.

Among the genotypes evaluated for 300kernel weight, modified hybrid Opener (102.15 g) showed bi value close to 1.0 and hence was comparatively stable in performance and generally adaptable across environments. Hybrid Hicorn with mean (X $=102.69 \mathrm{~g})$ and bi $=1.06$ could be considered slightly stable and adoptable to all environments. Modified hybrid WD-2x8 $(\mathrm{X}=108.11 \mathrm{~g}, \quad$ bi $=1.69)$ responded favourably to better environments but give poor yield in unfavourable environments. Hence, it could be more suitable for favourable environments. Low value of bi (0.36) made modified hybrid CS-2Y2 suitable for unfavourable environment due to its high mean value $(\mathrm{X}=107 \mathrm{~g})$. The stability analysis of 300-kernel weight revealed that modified hybrids showed better performance in ideal, favourable and unfavourable conditions. Grain yield is the most important trait in the development of maize hybrids. Identification of a genotype with high grain yield and stability is of immense value. Variances in genotype mean were used to evaluate stability of grain yield across environments. Regression coefficients (bi) and mean of four locations (X) are presented in Table 3. The regression coefficient (bi) values of the 10 genotypes used in this study ranged from 0.17 to 1.55
(Table 3) and there was no genotype with bvalues equal to 1.0. The variations in bivalues suggested that the genotypes responded differently to the varying environments. Variability among environments is an important factor and mostly determines the usefulness of $b$ values $[10,13]$. The regression coefficient values of modified hybrid WD-2x 8 were close to 1.0 $($ bi $\sim 1=0.90)$ with mean average yield $(8.43$ $\mathrm{t} \mathrm{ha}^{-1}$ ) at four locations greater than the overall mean. Modified hybrid Hicorn (X = $8.13 \mathrm{t} \mathrm{ha}^{-1}$ ) had regression coefficient (bi) equal to 0.88 . The grain yield of this genotype was fairly stable in varying environmental conditions. Similarly modified hybrid Opener $\left(\mathrm{X}=7.85 \mathrm{t} \mathrm{ha}^{-1}\right.$, bi $=1.36$ ) had high regression coefficient. The grain yield of this genotype was affected by varying environmental conditions and yield increased when the conditions were favourable and decreased to below average when the conditions were unfavourable. Small value of regression coefficient (bi = $0.50)$ and high value of mean grain yield $(X$ $=8.00 \mathrm{t} \mathrm{ha}^{-1}$ ), made hybrid Hicorn suitable for high yield under unfavourable environmental conditions.

Any generalization regarding the stability of a genotype for all the traits is quite difficult. The genotypes used in this study did not exhibit a uniform stability and response pattern for different traits. Different genotypes responded differently for different parameters. Overall, the performance and stability of modified hybrid WD-2x8 across different environments excelled other parental hybrids as well as modified hybrids. Selection of modified hybrid WD-2x8 for ear length, ear diameter, 300 kernel weight and grain yield could enhance the yield and it could be recommended as suitable and stable genotype for all four locations. Eberhart and Russell [8] suggested that, if the traits associated with high yield showed 
stability, the selection of genotype only for yield could be effective.

The production of a superior hybrid seed is a lengthy, time consuming and laborious job, if method of modified double cross hybrid production is adopted, the farmer may get seed of good quality at affordable price. It is justified from stability analysis and table of average maize grain yield, across four locations (Table 4), that production of modified double cross hybrids could be beneficial, as the yield of modified double cross hybrids were almost at par with their respective parental maize hybrids.

\section{Conclusions}

It is concluded from this study that modified double cross maize hybrids are as stable, across four locations, as compared to their respective single cross parental hybrids. Guillen-Portal et al. [15] also reported that double cross maize hybrids were generally more stable than the single cross maize hybrids. However, further studies are needed to confirm the adaptation of modified double cross hybrid across multiple environments.

\section{Authors' contributions}

Conceived and designed the experiments: SM Rasheed \& HU Rahman, Performed the experiments: Syed Majid Rasheed, Analyzed the data: SM Rasheed, Contributed reagents/ materials/ analysis tools: SM Rasheed, Wrote the paper: SM Rasheed \& HU Rahma.

\section{References}

1. Suinaga FA, Bastos CS \& Rangel LEP (2006). Phenotypic adaptability and stability of cotton cultivars in Mato Grosso State, Brazil. Pesq Agropec Bras 36: 145150.

2. Cruz CD \& Carneiro PCS (2006). Modelos biométricos aplicados ao melhoramento genético. UFV: Viçosa pp. 585.

3. Fan XM, Kang MS, Chen H, Zhang Y, Tan J \& Xu C (2007). Yield stability of maize hybrids evaluated in multi-environment trials in Yunnan, China. Agron J 99: 220228
4. Comstock RE \& Moll RH (1963). Genotypeenvironment interactions. Statistical Genetics and Plant Breeding (Hanson W.D. and Robinson H.F. editor), Washington D.C.: NAS-NRC Publication 982: 164-196.

5. Yilmaz, G \& Tugay ME (1999). Genotype $x$ environment interactions in potato $I$. the investigation based on stability parameters. Turkish J Agric Forestry 23: 97-105.

6. Yates F \& Cochran WG (1938). The analysis of groups of experiments. J Agric Sci 28: 556-580.

7. Finlay KW \& Wilkinson GN (1963). The analysis of adaptation in plant breeding programmes. Aus J Agric Res 14: 742-754.

8. Eberhart SA \& Russell WA (1966). Stability parameters for comparing varieties. Crop Sci 6: 36-40.

9. Dehghani H, Ebadi A \& Yousefi A (2006). Biplot analysis of genotype by environment interaction for barley yield in Iran. Agron J 98: 388-393.

10. Sabaghnia DNH \& Sabaghpour SH (2008). Graphic analysis of genotype $\times$ environment interaction of lentil yield in Iran. Agron J 100: 760-764.

11. Gul B, Marwat KB, Hussain G, Khan A, Hashim S \& Khan IA (2009). Impact of tillage, plant population and mulches on biological yield of maize. Pak J Bot 41(1): 2243-2249.

12. Russel WA (1984). Agronomic performance of maize cultivars representing different eras of breeding. Maydica 29: 375-390.

13. Akbar M, Saleem M, Ashraf MY, Hussain A, Azhar FM \& Ahmad R (2009). Combining ability studies for physiological and grain yield traits in maize at two temperatures. Pak J Bot 41(4): 1817-1829.

14. Williams JC, Penny LH \& Sprague GF (1965). Full sib and half sib estimates of genetic variance in an open pollinated variety of corn. Crop Sci 5: 125-129.

15. Guillen-Portal FR, Russell WK, Baltensperger DD, Eskridge KM, D'CrozMason NE \& Nelson LA (2003). Best types of maize hybrids for the western high plains of the USA. Crop Sci 43(4): 2065-2070. 